\title{
A Valorização da Biblioteca Escolar como Fonte de Informação
}

\author{
La valorización de la biblioteca escolar como fuente de información
} The Valorization of the School Library as an Information Source

\author{
Christian da Costa Simões ${ }^{1}$ \\ Elaine Corrêa Pereira ${ }^{2}$ \\ Lisiane de Pinho Coutinho da Costa ${ }^{3}$ \\ Celiane Costa Machado 4
}

\begin{abstract}
Resumo
O presente artigo tem como objetivo apresentar a biblioteca escolar como fonte de informação tanto para a escola quanto para a comunidade onde está inserida, mostrando a importância dessa para a construção do conhecimento e uma postura crítica dos alunos. A aproximação dos bibliotecários e professores da escola é necessária para o desenvolvimento da pesquisa escolar com os alunos e ainda reafirmando o espaço como fonte de informação, a biblioteca escolar é parte fundamental da aprendizagem e representação da escola.
\end{abstract}

Palavras-Chave: Biblioteca escolar; Bibliotecário escolar; Pesquisa escolar.

\section{Resumen}

El presente artículo tiene como objetivo presentar la biblioteca escolar como fuente de información tanto para la escuela y para la comunidad donde está inserta, mostrando la importancia de ésta para la construcción del conocimiento y una postura crítica de los alumnos. La aproximación de los bibliotecarios y profesores de la escuela es necesaria para el desarrollo de la investigación escolar con los alumnos y aún reafirmando el espacio como fuente de información, la biblioteca escolar es parte fundamental del aprendizaje y representación de la escuela.

Palabras claves: Biblioteca escolar; Bibliotecario escolar; Investigación escolar.

\begin{abstract}
This article aims to present the school library as a source of information for both the school and the community where it is inserted, showing the importance of this for the construction of knowledge and a critical posture of the students. The approach of school librarians and teachers is necessary for the development of school research with students and still reaffirming space as a source of information, the school library is a fundamental part of the school's learning and representation.
\end{abstract}

Keywords: School library; School librarian; School research.

\footnotetext{
${ }^{1}$ Graduando em Biblioteconomia e Bolsista PIBIC; Universidade Federal do Rio Grande - FURG; Rio Grande, Rio Grande do Sul, Brasil; christiansimoes98@gmail.com

${ }^{2}$ Doutora em Engenharia de Produção; Universidade Federal do Rio Grande - FURG; Rio Grande, Rio Grande do Sul, Brasil; elainepereira@ prolic.furg.br

${ }^{3}$ Pós-graduada em Educação Inclusiva e Bolsista EPEC; Universidade Federal do Rio Grande - FURG; Rio Grande, Rio Grande do Sul, Brasil; lisibn@gmail.com

${ }^{4}$ Doutora em Matemática Aplicada; Universidade Federal do Rio Grande - FURG; Rio Grande, Rio Grande do Sul, Brasil; celianecmachado@gmail.com
} 


\section{Introdução}

As bibliotecas são espaços de diálogo e produção do conhecimento, visto que, em seu acervo pode dispor de diversos tipos de materiais sejam eles físicos ou digitais. Esse espaço é organizado por um bibliotecário que presta serviços para a comunidade que utiliza a escola como por exemplo alunos, professores, diretores, auxiliares e pais. Com isso, cabe ao bibliotecário traduzir para uma linguagem comum ao público alvo contribuindo para o desenvolvimento do programa escolar.

Nesse ambiente escolar os professores programam as aulas de acordo com os conteúdos programáticos que necessitam serem abordados, procurando a melhor forma de tornar suas aulas dinâmicas e significativas. Como afirma Padilha (2001, p. 63), "lembramos que realizar planos e planejamentos educacionais e escolares significa exercer uma atividade engajada, intencional, científica, de caráter político e ideológico e isento de neutralidade". Sendo assim, para alcançar os objetivos que o professor busca para suas aulas é necessário fazer pesquisas em diversas fontes de informação para atingir diferentes pontos de vista.

O professor necessita buscar meios para a elaboração de sua aula e nesse sentido dentro do espaço escolar existe a biblioteca que serve como uma fonte de informação tanto para ele quanto para a turma. Conforme Garcia (1984, p. 10) "O professor deixa de ser mero transmissor de informações para se tornar um criador de estruturas para organização de informações." Atualmente a posição de ensinar requer sair do tradicional e buscar novas metodologias, com isso a biblioteca escolar apresenta-se como uma forma a mais de qualificar as aulas. Os sujeitos (bibliotecário e professor) atuam na maioria do tempo com alunos e isso exige conhecimento de informações sobre os temas das aulas e sobre os estudantes, para isso precisa haver diálogo entre ambos para atender a demanda das pesquisas dos alunos.

Assim, a presente pesquisa tem como objetivo apresentar a biblioteca escolar como fonte de informação tanto para a escola quanto para a comunidade onde está inserida, mostrando a importância dessa para a construção do conhecimento e uma postura crítica dos alunos. Para que isso seja possível é necessário reconhecer que o desenvolvimento da pesquisa escolar dentro da biblioteca se torne ativa e contribua para o ensino dos alunos. Dessa forma é fundamental a parceria entre professores e bibliotecários.

\section{Biblioteca escolar: um espaço de diálogo}

A biblioteca escolar é um dos vários tipos de bibliotecas que existem ao redor do mundo, cada uma com um público específico, mas tendo em comum a missão de atender as 
necessidades de informações das pessoas e ser um local de diálogo e interação. Assim como a biblioteca universitária atinge um publico maior de adultos, a biblioteca escolar atinge o publico maior de crianças e adolescentes, por se tratar de um ambiente dentro da escola.

O documento Diretrizes da IFLA/UNESCO para bibliotecas escolares é essencial para a representação da mesma

A biblioteca escolar propicia informação e idéias que são fundamentais para o sucesso de seu funcionamento na sociedade atual, cada vez mais baseada na informação e no conhecimento. A biblioteca escolar habilita os alunos para a aprendizagem ao longo da vida e desenvolve sua imaginação, preparando-os para viver como cidadãos responsáveis. (IFLA/UNESCO, 2002, p. 4)

A biblioteca é um local de desenvolvimento pessoal e coletivo presente nas escolas, um lugar que possui uma tradição de fornecer apoio bibliográfico e lazer para quem busca por isso, conforme afirma Corte e Bandeira (2011, p. 8) "a biblioteca escolar é um espaço de estudo e construção do conhecimento, coopera com a dinâmica da escola, desperta o interesse intelectual, favorece o enriquecimento cultural e incentiva a formação do hábito de leitura." $\mathrm{Na}$ atualidade, esse espaço também se configura por demonstrar participação em atividades comemorativas e representativas da região e país para as turmas da escola, evidenciando a história e costumes.

É comum na biblioteca escolar a existência da contação de histórias para as turmas, essa atividade tem grande contribuição para a formação do leitor, pois o contar e ouvir atribuem a posição do leitor (GIROTTO; SOUZA, 2009). Essa é mais uma construção que se tem a partir desse espaço como um ambiente participativo da escola e favorecedor do desenvolvimento dos seus alunos.

No entanto, a biblioteca possui muitas formas de contribuir para a comunidade escolar que vão além de datas comemorativas e contação de história, o seu acervo é essencial para a consulta de pesquisas. Por isso a relação também deve ser entre bibliotecário e professor para que:

Cada escola deverá desenvolver seu próprio programa de literatura de acordo com a história de vida e as habilidades das crianças que atende. O professores e bibliotecários devem conhecer suas crianças, quanto o potencial do material disponível, além de compreender a estrutura da literatura; a partir dai eles estarão aptos a fazer a correspondência entre criança e livro. (SANTOS; SOUZA, 2009, p. 98)

A relação biblioteca e internet é responsável por apresentar ao aluno um vasto campo de possibilidades de consulta. Aliando ao acesso à internet, potencializa a formulação de ideias estimulando a verificação dos endereços eletrônicos que são encontrados. Dentro da 
biblioteca ainda pode existir oficinas e cursos de capacitação para alunos, professores e a comunidade para a utilização das fontes de informação.

\subsection{Bibliotecário escolar}

O bibliotecário deve sempre manter-se atualizado e encontrar formas de relacionar o tradicional com o novo, fazer com o que já existe vire algo novo e interessante para estimular a utilização da biblioteca e de seu material. Possuindo ou não acesso a internet ele deve ser capaz de organizar e acompanhar os alunos ao uso da biblioteca escolar, para isso Corrêa et al (2002, p. 116) afirmam que "o bibliotecário escolar tem uma tarefa difícil: cativar e conquistar o estudante e fazer com que este se sinta à vontade na biblioteca escolar." Ainda nas palavras dos autores:

O bibliotecário precisa participar ativamente de todos os acontecimentos que circundam o ambiente escolar, bem como ter conhecimento da política educacional da instituição na qual atua, estando atento a todos os aspectos que envolvem seu trabalho no contexto escolar, interagindo também através da parte técnica necessária ao bom funcionamento da biblioteca. (CORRÊA et al., 2002, p. 118)

A presença do bibliotecário no contexto escolar é essencial para a dinamização da biblioteca, de tal forma que seja vista como parte fundamental da escola. Conhecer as políticas educacionais fazem parte da função desse profissional que precisa buscar recursos para as atividades da biblioteca. Com isso, acaba sendo possível saber quanto a escola terá de verba para a compra de material para a biblioteca, se a escola poderá participar de algum edital para conseguir verba e ao mesmo tempo mostrar a importância da biblioteca e do bibliotecário nas reuniões de classe. A presença do profissional na biblioteca pode desenvolver o espaço e reconhecimento de sua missão segundo Côrte e Bandeira:

O bibliotecário de referência existe para atender às necessidades de informação do leitor. É sempre bom ter em mente que a biblioteca é uma unidade dinâmica e atua de forma sistemática, em que todas as interagem e se complementam. Os demais serviços, como seleção, aquisição, catalogação, classificação e preparação física do documento, são preparatórios para a atividade de atendimento ao usuário. (CÔRTE; BANDEIRA, 2011, p. 105)

A biblioteca é um espaço vivo e feito para a comunidade e o bibliotecário contribui para a formação dos alunos tanto quanto o professor. No momento que se necessita de uma consulta na biblioteca, todos os outros setores dela entram em ação para efetivar o serviço de referência. Tudo isso mostra a capacidade que se tem através da biblioteca escolar para a construção dos saberes.

No mesmo sentido que são apresentados os professores e a direção, aos pais e/ou responsáveis pelos alunos o bibliotecário pode e deve se mostrar presente as famílias, afinal a 
biblioteca é parte da escola e nela pode se conhecer futuros leitores e desde cedo aperfeiçoar a escrita. Segundo Caldin,

O bibliotecário tem uma responsabilidade enorme, pois dependerá dele (de seus próprios valores e crenças), o resultado das ações efetuadas dentro da biblioteca. Se ele considerar a educação em um sentido amplo, não limitado somente ao ensino, mas, principalmente, voltada à formação de hábitos e atitudes do aluno, ele não se restringirá a ser um mero técnico-administrativo a serviço da escola. Ele irá lutar pela conquista da igualdade de oportunidades sociais que possibilitem a todos os estudantes o acesso ao conhecimento registrado. (CALDIN, 2005, p. 164)

Para o bibliotecário escolar que atua com vontade e interesse de contribuir na aprendizagem dos alunos, a função é natural ao seu proposito de atender as necessidades de informação de seus usuários. O bibliotecário nesse ambiente tem a responsabilidade de ao lado do professor proporcionar o gosto pela pesquisa, mostrar que a pesquisa escolar visa desenvolver no aluno, um senso crítico.

\subsection{O bibliotecário e o professor ativos na escola}

O bibliotecário e o professor atuam diretamente na escola e com os estudantes, um na sala de aula e o outro na biblioteca, mas esses dois espaços podem se cruzar? A resposta é clara e bem possível de acontecer, basta a vontade de fazer acontecer a melhoria do âmbito escolar. A biblioteca escolar quando dispõe de recursos fundamentais será um espaço de formação permanente para bibliotecários e professores, permitindo assim uma reflexão do seu papel e sua avaliação crítica das atividades (MAROTO, 2009).

A união entre bibliotecário e professor é essencial para a potencialização da biblioteca escolar e a representatividade que a mesma tem para a escola. Com a parceria entre os dois profissionais é possível atingir um nível maior de estudantes a fim de conhecer mais sobre o espaço para pesquisas e lazer. Segundo as diretrizes da IFLA/UNESCO para bibliotecas escolares essa parceria entre bibliotecários e professores deve existir para:

\footnotetext{
Desenvolver, instruir e avaliar o aprendizado dos alunos conforme previsto no programa escolar; Desenvolver e avaliar habilidades no uso e conhecimento da informação pelos alunos; Desenvolver planos de aula; Preparar e realizar projetos especiais de trabalho, num ambiente mais amplo de aprendizagem, incluindo a biblioteca; Preparar e realizar programas de leitura e eventos culturais; Integrar tecnologia de informação ao programa da escola; Oferecer esclarecimentos aos pais sobre a importância da biblioteca escolar. (IFLA/UNESCO, 2002, p. 12)
}

Deve haver um diálogo entre professor e o bibliotecário para que ambos possam desenvolver juntos suas atividades. A biblioteca escolar pode ser uma extensão da sala de aula, um espaço com um acervo a disposição para a realização das tarefas escolares e ainda despertar novas ideias para as aulas e nos horários vagos ainda ser local de lazer para os 
alunos que tem o hábito de leitura. Desse modo os dois profissionais podem estimular o gosto pela pesquisa dos alunos e apresentar o espaço da biblioteca para a comunidade.

O bibliotecário pode participar como um apoiador das aulas e ao mesmo tempo atua como um educador em momentos que são necessários como no uso do ambiente da biblioteca escolar e as atividades que são propostas pela mesma, A sua participação para o funcionamento desse espaço serve para organizar tecnicamente e colaborar nas fontes de informação, assim como as demais funções de uma biblioteca escolar que este profissional é apto para exercer.

A biblioteca escolar contribui para a aproximação dos alunos com os livros e despertando a vontade de buscar novos materiais de informação, o bibliotecário apresenta então nova possíveis formas de buscas pela informação e ainda orienta para uma pesquisa mais detalhada dos temas solicitados. Assim, para que a relação comunidade e escola aconteça é preciso que professores e bibliotecários desenvolvam atividades que apresentem e estimulem o propósito desse lugar para essas pessoas, que seja um local de transformação (MAROTO, 2009).

\subsection{Pesquisa escolar}

Na sala de aula os alunos são acostumados a realizar tarefas que necessitam de uma busca para esclarecer conceitos sobre algum tema solicitado pelo professor, o que acaba acontecendo muitas vezes é que o retorno dessas tarefas fica no copia e cola e não sendo explorado o potencial que o aluno tem em se posicionar.

As tarefas acabam sendo simples e não despertam o desafio em buscar novos caminhos para a consulta. Nesse momento que o bibliotecário e o professor são peças fundamentais para mudar essa realidade. Suas orientações são úteis para a realização das pesquisas dos alunos e ainda tornar a pesquisa escolar um habito a ser seguido.

Segundo Moraes, Valadares e Amorim (2013), o papel educativo que se busca é que exista um processo de cooperação pedagógica, assim criando uma parceria colaborativa nas atividades. A união precisa acontecer para os resultados serem positivos aos alunos, quando se tem o apoio do professor e bibliotecários realizando atividades em conjunto os resultados surgem, ampliando a aprendizagem dos alunos.

A atividade de pesquisa escolar pode ser desenvolvida mediante ao acervo físico da biblioteca ou em meio digital e até os dois suportes ao mesmo para atender a demanda de informação, mas jamais deve ser ignorado a verificação de fontes por isso, a orientação do bibliotecário se faz presente no momento da prática. 
Como afirmam Caldas, Silva e Ramires (1995), a pesquisa escolar faz parte da rotina das aulas e os alunos devem buscar e resumir informações de várias fontes bibliográficas. A investigação é parte da ação de pesquisar e pode ser desenvolvida na biblioteca escolar pelo bibliotecário. O uso de ferramentas tecnológicas para a realização das pesquisas é útil, mas a atenção deve ser redobrada, pois o nível de distração é maior já que na internet o acesso é muito mais rápido.

No momento que a turma é apresentada para a biblioteca escolar o bibliotecário pode orientar sobre a importância de referenciar o documento de onde foram retiradas as informações da pesquisa. A atividade de busca para a realização da pesquisa escolar deve ser feita com atenção e na biblioteca os alunos receberão a orientação necessária para isso, os diferentes suportes são apresentados pelo bibliotecário e também a melhor forma de utilização.

A biblioteca escolar faz parte do desenvolvimento dos alunos e precisa ser explorada ao máximo a fim de beneficiar a comunidade escolar para o presente e o futuro. O seu espaço é uma fonte de informação representativa da escola e capaz de gerar o conhecimento, podendo ser o ambiente mais apropriado para aqueles que buscam informação.

\section{Considerações finais}

A presente pesquisa teve o objetivo de apresentar a biblioteca escolar como fonte de informação tanto para a escola quanto para a comunidade onde está inserida, mostrando a importância dessa para a construção do conhecimento e uma postura crítica dos alunos. Nesse sentido percebe-se que a utilização da biblioteca escolar é uma forma de organização pedagógica para as atividades de pesquisa escolar que são realizadas na escola com as turmas. Pode se olhar a biblioteca como uma extensão da sala de aula, o ensinar e aprender é característico desses espaços. Nesse sentido há necessidade de uma parceria entre professores e bibliotecários para a efetivação da biblioteca como fonte de informação. As bibliotecas contemplam a interdisciplinaridade pois possuem em seu acervo obras de muitas áreas do conhecimento, o que pode contribuir na contextualização das aulas.

A biblioteca escolar contribui na formação dos alunos e no desenvolvimento das aulas para os professores. A realização da pesquisa na biblioteca escolar é uma forma de potencialização dos seus recursos e do profissional responsável, o bibliotecário. A extensão que se dá por meio do seu espaço como uma fonte de informação é necessária para a escola. Os professores, ao levar suas turmas para a biblioteca e junto com o bibliotecário apresentar os materiais que podem ser usados para informação das pesquisas, farão com que esses 
estudantes valorizem esse ambiente como fonte de informação, proporcionando conhecimento, lazer e cultura.

\section{Referências}

CALDAS, Maria Aparecida Esteves; SILVA, Sinézia Cecília de Araújo e; RAMIRES, Gilka Ferreira Gomes. Pesquisa escolar: conhecimento e utilização de fontes bibliográficas. Recife: Bagaço, 1995.

CALDIN, Clarice Fortkamp. Reflexões acerca do papel do bibliotecário de biblioteca escolar. Revista ACB, [S.1.], v. 10, n. 2, p. 163-168, jan. 2006. ISSN 1414-0594. Disponível em: <https://revista.acbsc.org.br/racb/article/view/431/550>. Acesso em: 26 dez. 2018

CÔRTE, Adelaide Ramos e; BANDEIRA, Suelena Pinto. Biblioteca escolar. Brasília, DF: Briquet de Lemos, 2011.

CORREA, Elisa Cristina Delfini et al. Bibliotecário escolar: um educador?. Revista ACB, [S.1.], v. 7, n. 1, p. 107-123, ago. 2005. ISSN 1414-0594. Disponível em: <https://revista.acbsc.org.br/racb/article/view/379/459>. Acesso em: 26 dez. 2018.

GARCIA, Consuelo de M. Planejamento de ensino: fase de preparação. Educ. rev., Curitiba, n. 3, p. 9-34, dez. $1984 . \quad$ Disponível em $<$ http://www.scielo.br/scielo.php?script=sci_arttext\&pid=S0104$40601984000100003 \& \operatorname{lng}=$ en\&nrm=iso>. Acesso em 24 dez. 2018.

GIROTTO, Cyntia G. G. S.; SOUZA, Renata Junqueira de. A hora do conto na biblioteca escolar: o diálogo entre a leitura e outras linguagens. In: SOUZA, Renata Junqueira de. Biblioteca escolar e práticas educativas: o mediador em formação. Campinas: Mercado de letras, 2009, p. 19-47.

MAROTO, Lucia Helena. Biblioteca escolar, eis a questão! Do espaço do castigo ao centro do fazer educativo. Belo Horizonte: Autêntica, 2009.

MORAES, Fabiano; VALADARES, Eduardo; AMORIM, Marcela Mendonça. Alfabetizar letrando na biblioteca escolar. São Paulo: Cortez, 2013.

PADILHA, P. R. Planejamento Dialógico: Como construir o projeto político pedagógico da escola. São Paulo: Ed. Cortez, 2001.

SANTOS; Caroline C. S. dos; SOUZA, Renata Junqueira de. Programas de leitura na biblioteca escolar: a literature a serviço da formação de leitores. In: SOUZA, Renata Junqueira de. Biblioteca escolar e práticas educativas: o mediador em formação. Campinas: Mercado de letras, 2009, p. 97-114.

UNESCO/IFLA. Directrizes da IFLA/UNESCO para bibliotecas escolares. 2002. Disponível em: <https://www.ifla.org/files/assets/school-libraries-resourcecenters/publications/school-library-guidelines/school-library-guidelines-pt.pdf $>$. Acesso em: 24 nov. 2018. 